\title{
Enrichment of small pathogenic deletions at chromosome 9p24.3 and 9q34.3 involving DOCK8, KANK1, EHMT1 genes identified by using high-resolution oligonucleotide-single nucleotide polymorphism array analysis
}

\author{
Jia-Chi Wang* (D), Loretta W. Mahon, Leslie P. Ross, Arturo Anguiano, Renius Owen and Fatih Z. Boyar
}

\begin{abstract}
Background: High-resolution oligo-SNP array allowed the identification of extremely small pathogenic deletions at numerous clinically relevant regions. In our clinical practice, we found that small pathogenic deletions were frequently encountered at chromosome $9 p$ and $9 q$ terminal regions.

Results: A review of 531 cases with reportable copy number changes on chromosome 9 revealed 142 pathogenic copy number variants (CNVs): 104 losses, 31 gains, 7 complex chromosomal rearrangements. Of 104 pathogenic losses, 57 were less than $1 \mathrm{Mb}$ in size, enriched at 9p24.3 and 9q34.3 regions, involving the DOCK8, KANK1, EHMT1 genes. The remaining 47 cases were due to interstitial or terminal deletions larger than $1 \mathrm{Mb}$ or unbalanced translocations. The small pathogenic deletions of DOCK8, KANK1 and EHMT1 genes were more prevalent than small pathogenic deletions of NRXN1, DMD, SHANK3 genes and were only second to the 16p11.2 deletion syndrome, 593-kb (OMIM \#611913).
\end{abstract}

Conclusions: This study corroborated comprehensive genotype-phenotype large scale studies at 9p24.3 and 9q24.3 regions for a better understanding of the pathogenicity caused by haploinsufficiency of the DOCK8, KANK1 and EHMT1 genes.

Trial registration number: None; it is not a clinical trial, and the cases were retrospectively collected and analyzed.

Keywords: Small pathogenic deletions, High resolution oligonucleotide-single nucleotide polymorphism array analysis, Haploinsufficiency, Homozygous deletions

\section{Background}

Chromosomal microarray analysis (CMA) has been widely utilized for the genome-wide screening of microdeletion and microduplication syndromes [1]. The sizes of well-known microdeletion and microduplication syndromes were usually larger than $1 \mathrm{Mb}$, such as $1.4 \mathrm{Mb}$ for Williams-Beuren syndrome (OMIM \#194050) or $2.8 \mathrm{Mb}$ for DiGeorge syndrome (OMIM \#188400). Small

\footnotetext{
* Correspondence: jia-chi.j.wang@questdiagnostics.com; sjackwang1968@gmail.com

Cytogenetics Laboratory, Quest Diagnostics Nichols Institute, 33608 Ortega

Highway, San Juan Capistrano, CA 92690, USA
}

$(<1 \mathrm{Mb})$ pathogenic deletions at regions which were not well characterized were frequently encountered during our daily clinical practice, for instance, the chromosomal regions at $9 \mathrm{p} 24.3$ and $9 \mathrm{q} 34.3$.

High-resolution oligo-SNP array is able to reveal a variety of chromosomal disorders including uniparental disomy or extremely small pathogenic deletions which would be missed by low-resolution oligonucleotide CMA. Our and other previous studies showed the cases with uniparental disomy were relatively limited in number on chromosome 9 as compared to chromosome 15, 11 and $7[2,3]$. In contrast, small pathogenic deletions 
were frequently encountered at chromosome 9p24.3 and 9 q34.3 by using high-resolution oligo-SNP array in postnatal studies. Research endeavors have been significantly prioritized to specific genes such as NRXN1 and SHANK3 in the past $[4,5]$. To the best of our knowledge, only four cases with small deletions of $192 \mathrm{~kb}$, $225 \mathrm{~kb}, 465 \mathrm{~kb}$ and $518 \mathrm{~kb}$ in size at 9p24.3 involving the DOCK8 and/or KANK1 gene [6-8], and a case of $40 \mathrm{~kb}$ deletion in the EHMT1 gene at 9q34.3 [9] have been documented.

The purpose of this study is to evaluate 1): the incidence of small $(<1 \mathrm{Mb})$ pathogenic deletions in postnatal specimens, 2): whether the small pathogenic deletions at 9p24.3 and 9q34.3 constituted a significant proportion of small deletions, 3): what proportion of deletions on chromosome 9 was caused by small pathogenic deletions at 9p24.3 and 9q34.3, 4): the efficacy of identifying extremely small homozygous pathogenic deletions using high-resolution oligo-SNP array.

\section{Results}

The incidence of small pathogenic deletions in postnatal specimens studied by high-resolution oligo-SNP array

Approximately 38,000 postnatal specimens were studied by high-resolution oligo-SNP array in our laboratory from 2011 through 2015. Of these, we reported approximately $13,000(34 \%)$ pathogenic variants or variants of uncertain clinical significance (VOUS). The detection rate was consistent with our previous study [2]. Of the 13,000 variants, a total of 373 recurrent (at least 3 cases) small pathogenic losses were identified (Fig. 1). The 16p11.2 deletion syndrome, 593-kb (OMIM \#611913) is the most common small pathogenic loss (107 cases). The remaining involved NRXN1 (35 cases), DMD (31 cases), DOCK8 and/or KANK1 (30 cases), and other chromosomal regions such as 16p11.2 (OMIM \#613444, 220-KB), 16p12.2 (OMIM \#136570, 520-KB), 22q13.33 (OMIM \#606232).

\section{Approximately $12 \%$ of the recurrent small pathogenic copy number losses were caused by deletions of DOCK8 andKANK1 at 9p24.3 and EHMT1 at 9q34.3}

The total number of deletions involving DOCK 8 and/or KANK1 genes at 9p24.3 (30 cases, Fig. 2) and EHMT1 gene at 9q34.3 (16 cases, Fig. 3a) constituted approximately $12 \%$ (46/373 cases) of the recurrent small pathogenic deletions from all the chromosomes.

Small $(<1 \mathrm{Mb})$ and relatively small $(1-1.5 \mathrm{Mb})$ deletions constituted $59 \%$ of pathogenic copy number losses on chromosome 9

Of 13,000 cases with reported copy number variants (CNVs), 531 cases were from chromosome 9, and 142 were pathogenic, including 104 losses, 31 gains, 7 complex chromosomal rearrangements with both losses and gains (Table 1 and Additional file 1: Figure S1). Of 104 pathogenic losses, 57 were smaller than $1 \mathrm{Mb}$ in size. Of 57 cases, 46 were located at 9p24.3 and 9q34.3 regions, involving the DOCK8, KANK1, EHMT1 genes. The size ranged from $22 \mathrm{~kb}$ (case 54 with EHMT1 deletion) to

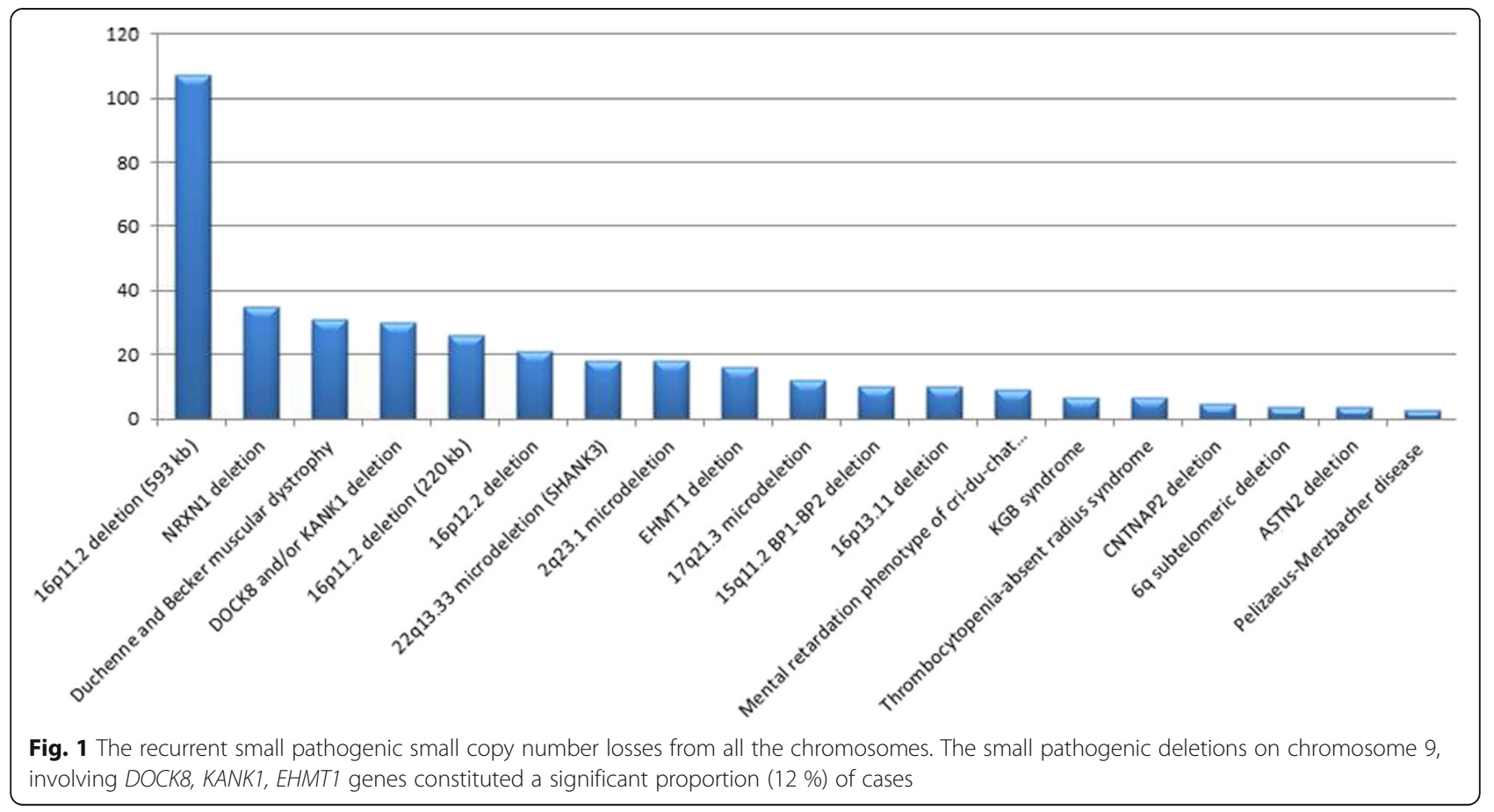




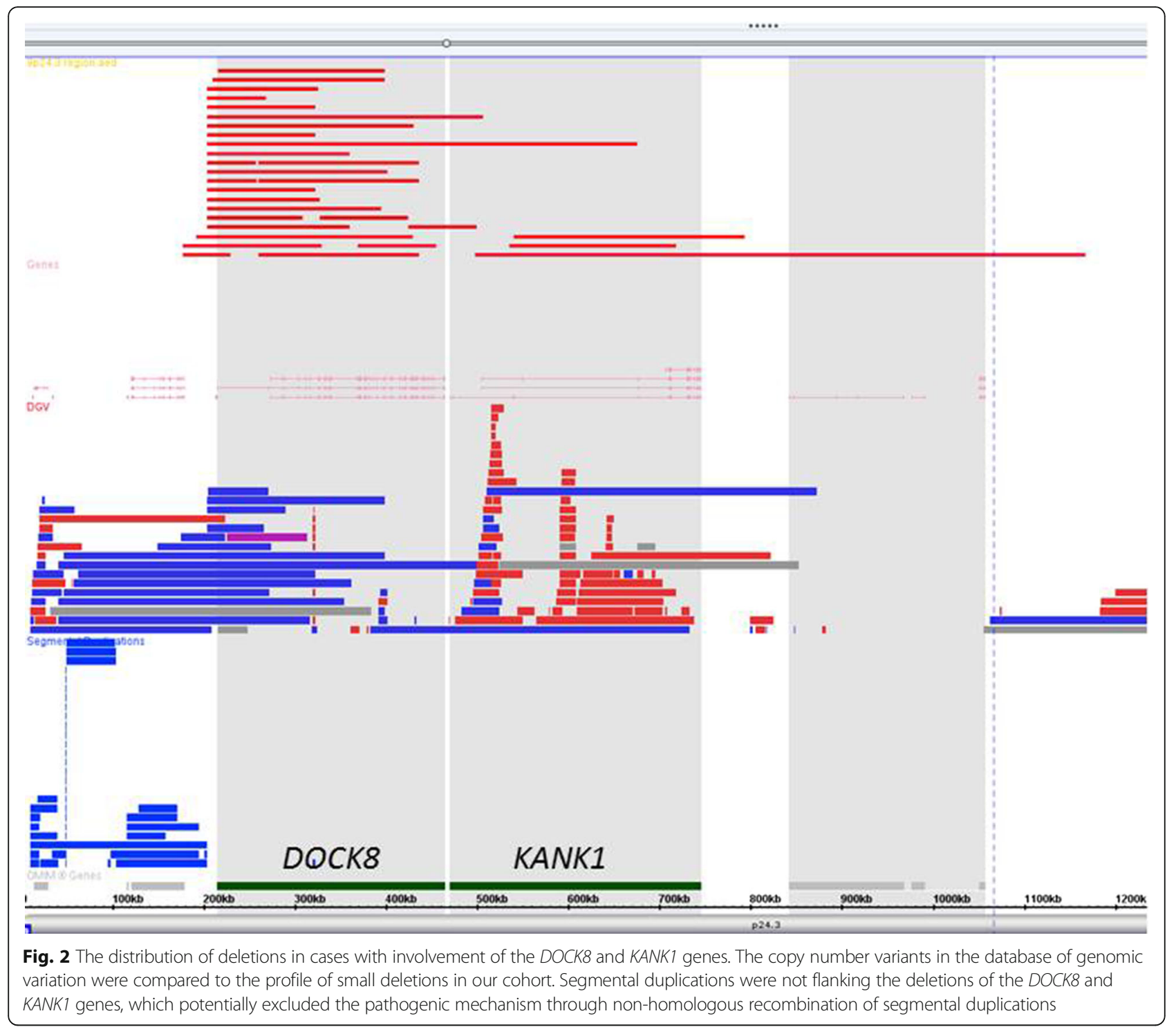

$790 \mathrm{~kb}$ (case 35), with an average of $384 \mathrm{~kb}$ (Table 1 and Additional file 2: Table S1). The remaining 47 cases were either resulted from interstitial deletions over $1 \mathrm{Mb}$ in size (18 cases), terminal deletions over $1 \mathrm{Mb}$ (14 cases), or unbalanced translocations (15 cases) that could be as small as $880 \mathrm{~kb}$ in size in a $\mathrm{t}(9 ; 11)(\mathrm{q} 34.3 ; \mathrm{p} 15.4)$ (case 47 , Additional file 2: Table S2). Very interestingly, of these 47 cases, four had relatively small deletions (1-1.5 Mb in size): a 1,048-kb deletion (case 10, Additional file 2: Table S2) involving the PTCH1 gene (OMIM 601309) and diagnosis of Gorlin syndrome (OMIM \#109400), a 1,349-kb deletion (case 15) involving the STXBP1 gene and diagnosis of early infantile epileptic encephalopathy (OMIM \#612164), and two 9q34.3 deletions of $1,218 \mathrm{~kb}$ and $1,268 \mathrm{~kb}$ (case 31 and 32). The small (57 cases) and relative small (4 cases) deletions established $59 \%(61 / 104)$ of pathogenic copy number losses on chromosome 9.

\section{The 9p24.3 (0-2.2 Mb from 9p telomere) and 9q34.3} (137.4-141.2 Mb from 9p telomere) were two hot spots of pathogenic copy number losses on chromosome 9

The 9p24.3 and 9q34.3 regions were two hot spots of copy number losses on chromosome 9. A total of 35 cases majorly involved the 9p24.3 region: 30 small pathogenic deletions (case 1-30, Additional file 2: Table S1), one interstitial deletion (case 1, Additional file 2: Table S2), two terminal deletions (case 19 and 20), and two unbalanced translocations (case 33 and 35). Additionally, 26 cases were localized to $9 q 34.3$ region: 17 small pathogenic deletions (case 41-57, Additional file 2: Table S1), one interstitial deletion (case 18, Additional file 2: 

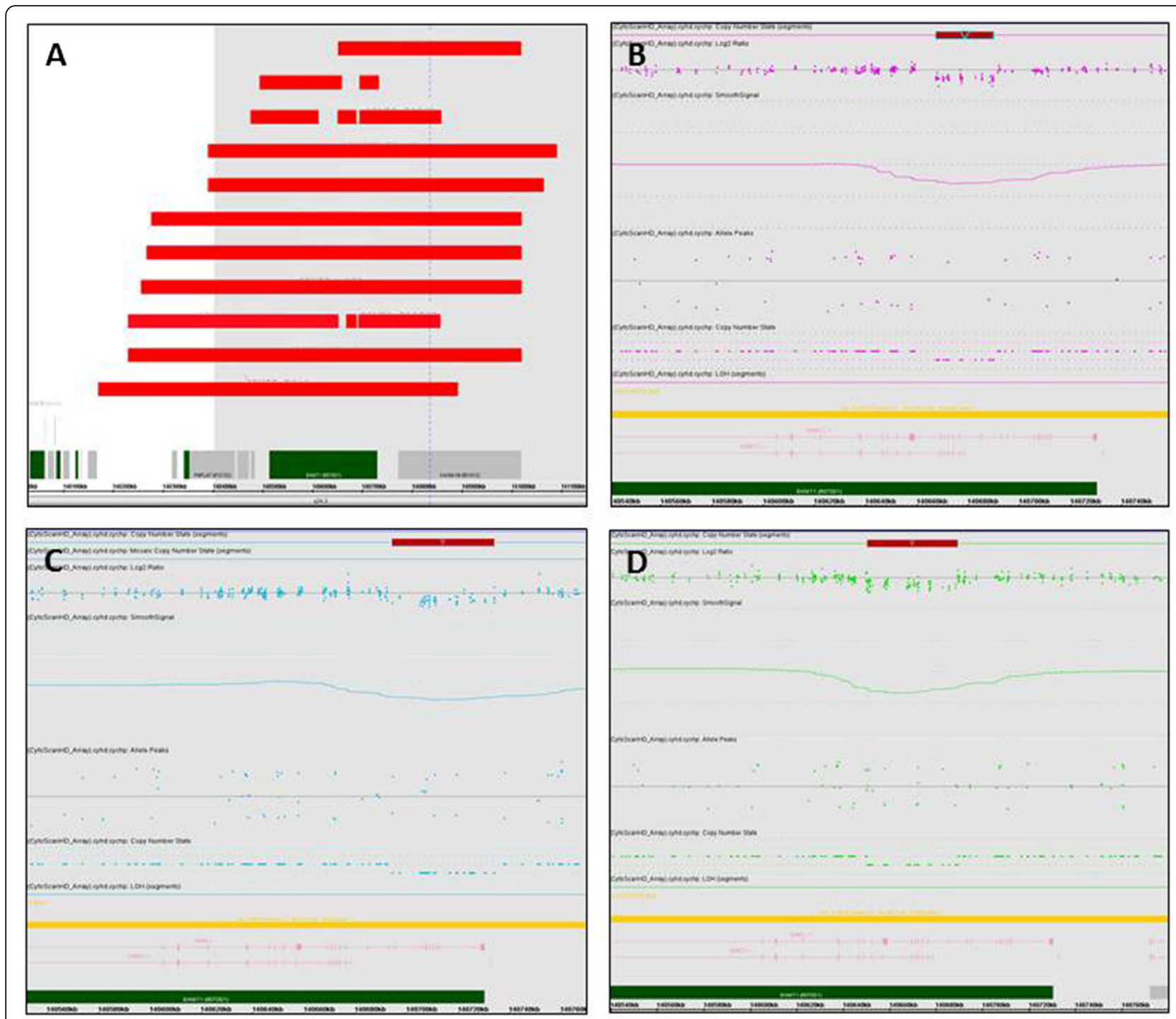

Fig. 3 a The genomic locations of the 16 small ( $<1$ Mb) pathogenic deletions involving the EHMT1 gene. b. A 22-kb deletion (chr9:140,667,619-140,689,934) was found in 32-year-old female with intellectual disability. c A 40-kb deletion (chr9:140,694,541-140,734,178) was identified in a 5-year-old girl. d A 39-kb deletion (chr9:140,650,471-140,689,373) was discovered in a 1-year-old girl with developmental delay, speech and motor delay, white matter changes on MRI, and hypotonia

Table S2), 5 large terminal deletions (case 28-32) and 3 unbalanced translocations (case 45-47). Overall, close to $60 \%(61 / 104,59 \%)$ of deletions were localized to the very ends of chromosome 9 at band 9p24.3 and 9q34.3.

\section{Rarely encountered extremely small homozygous pathogenic deletions were discovered in two cases}

Extremely small homozygous pathogenic deletions were identified in two cases: 1): a new born baby girl who presented with a metabolic disorder (abnormal reflexes, hypotonia, seizures, and elevated glycine) was revealed to contain a 25-kb homozygous deletion in the GLDC gene, which gave rise to autosomal recessive glycine encephalopathy (nonketotic hyperglycinemia; OMIM \#605899). Besides that, a 50-kb heterozygous deletion was also found in the $5^{\prime}$ region of the GLDC gene. Parental study showed the mother was a carrier of a $25-\mathrm{kb}$ heterozygous deletion and the father was a carrier of a $75-\mathrm{kb}$ heterozygous deletion of the GLDC gene. The $25-\mathrm{kb}$ maternally inherited deletion was located within the 75-kb paternally inherited deletion, and therefore inheritance of abnormal allele from both parents led to a $25-\mathrm{kb}$ homozygous and a 50-kb heterozygous deletion in the proband (Fig. 4); 2): a 1-year-old boy was found to have a 74$\mathrm{kb}$ homozygous deletion of the CDK5RAP2 gene in a region of homozygosity (Additional file 3: Figure S2) which 
Table 1 Profile of pathogenic copy number losses and gains in chromosome 9

\begin{tabular}{|c|c|c|c|}
\hline Type or gene involved & Number & Mean, kb & Range, kb \\
\hline \multicolumn{4}{|l|}{ Copy number losses : large } \\
\hline Interstitial deletion & 18 & 5,070 & $1,048-16,837$ \\
\hline Terminal deletion & 14 & 5,273 & $1,218-13,593$ \\
\hline Unbalanced translocation & 15 & 7,053 & $880-17,107$ \\
\hline Subtotal & 47 & & \\
\hline \multicolumn{4}{|l|}{ Copy number losses: small } \\
\hline DOCK8 & 24 & 299 & $97-431$ \\
\hline KANK1 & 3 & 369 & $184-670$ \\
\hline DOCK8 and KANK1 & 3 & 419 & $75-676$ \\
\hline EHMT1 & 16 & 417 & $22-790$ \\
\hline ASTN2 & 4 & 150 & $78-271$ \\
\hline FREM1 & 2 & 369 & $166-573$ \\
\hline STXBP1 & 1 & 592 & NA \\
\hline COL5A1 & 1 & 370 & NA \\
\hline GLDC & 1 & 50 & $25-75$ \\
\hline TOPORS & 1 & 337 & NA \\
\hline CDK5RAP2 & 1 & 74 & NA \\
\hline Subtotal & 57 & & \\
\hline \multicolumn{4}{|l|}{ Large copy number gains } \\
\hline Trisomy 9p/proximal 9q & 15 & 45,996 & $13,826-95,453$ \\
\hline 9q duplications & 6 & 12,172 & $6,277-18,399$ \\
\hline Unbalanced translocation & 4 & 25,717 & $6,794-68,089$ \\
\hline Tetrasomy $9 q$ and proximal $9 q$ due to isochromosome & 3 & 66,477 & $49,843-81,113$ \\
\hline Trisomy 9 & 2 & 140,833 & NA \\
\hline Triplication & 1 & 15,972 & NA \\
\hline Subtotal & 31 & & \\
\hline \multicolumn{4}{|l|}{ Complex chromosomal rearrangements (CCRs) } \\
\hline Inverted duplication with terminal deletion of 9p & 3 & \multicolumn{2}{|c|}{ Deletion: 6,377; Duplication: 32,271 } \\
\hline Inverted duplication with terminal deletion of 9q & 1 & \multicolumn{2}{|c|}{ Deletion: 161; Duplication: 3,127 } \\
\hline Multiple deletion and duplication & 2 & \multicolumn{2}{|c|}{ Losses: 1091; Gains: 12,517} \\
\hline Chromothripsis & 1 & \multicolumn{2}{|c|}{ Loss: 134; Gains: 21,094 } \\
\hline Subtotal & 7 & & \\
\hline Total & 142 & & \\
\hline
\end{tabular}

NA not applicable

led to autosomal recessive primary microcephaly-3 (OMIM \#604804). The presence of multiple large regions of homozygosity (a total of $421 \mathrm{Mb}$ ) implied these two parents were closely related in blood. The proband inherited the heterozygous abnormal allele with deletion of the CDK5RAP2 gene from both parents.

\section{Discussion}

The subtelomeric region such as $1 \mathrm{p} 36$ is known to be gene-rich and prone to have deletions, supported by a study with a large cohort of over 5,000 cases [10]. The cases with subtelomeric rearrangements comprised of about $46 \%$ of all the genomic abnormalities identified by CMA [10]. However, as compared to $1 \mathrm{p} 36,22 \mathrm{q} 13$, $4 \mathrm{p} 16,5 \mathrm{p} 15$, very limited cases at the ends of chromosome $9 p$ and $9 q$ were established [10]. When we reviewed the profile of copy number losses from our database of 38,000 postnatal cases studied by using high-resolution oligoSNP array and sorted it based on chromosomal regions, we discovered that all the cases with $1 \mathrm{p} 36$ deletions were over $1 \mathrm{Mb}: 20$ cases were 1-3 Mb, eight cases were 3$5 \mathrm{Mb}$, eight cases were $5-10 \mathrm{Mb}$ and five cases were 10 


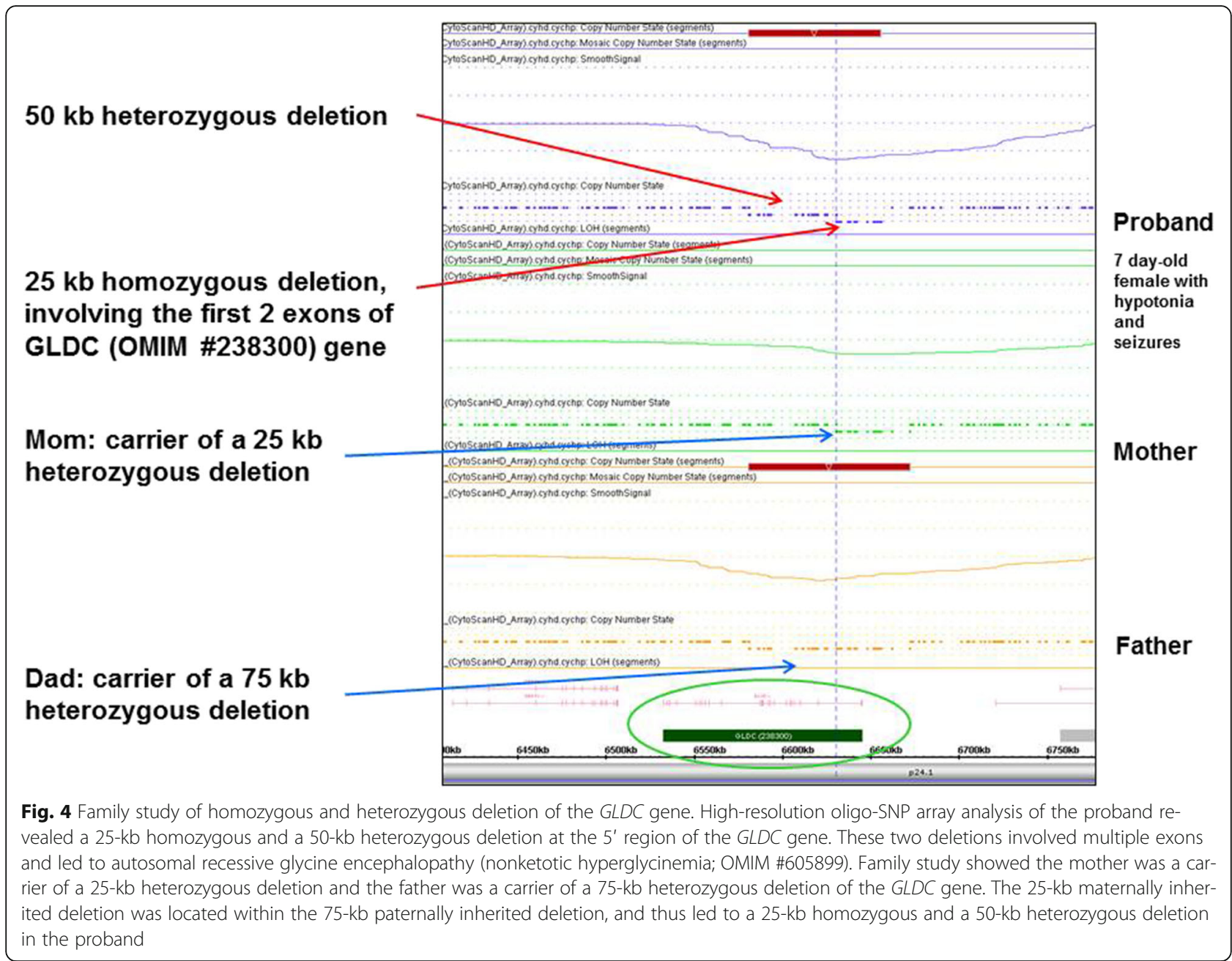

$20 \mathrm{Mb}$ in size (unpublished data). In contrast, 61 of 104 pathogenic deletions on chromosome 9 were either smaller than $1 \mathrm{Mb}$ (57 cases) or between 1 and $1.5 \mathrm{Mb}$ (4 cases). This finding demonstrated that the size of copy number losses conspicuously varied between chromosomal regions. In the clinical practice, the concept of vigilant selecting appropriate methods to characterize the genomic losses at different regions becomes essentially important. For instance, FISH analysis using subtelomeric or locus-specific probe may be approriate to identify $1 \mathrm{p} 36$ microdeletions, but may miss cases with small deletions on chromosome 9 .

Extremely small intragenic deletion of the EHMT1 gene was only reported in one case: a 40-kb intragenic deletion of the EHMT1 gene with uncertain phenotypic consequence [9]. A more recent update on Kleefstra syndrome exhibited that the 16 newly diagnosed 9q34.3 deletions were all larger than $200 \mathrm{~kb}$ [11]. In our cohort, we identified a total of 24 cases with $9 \mathrm{q} 34.3$ deletions: 16 with small $(<1 \mathrm{Mb})$ deletions involving the EHMT1 gene (case 42-57, Additional file 2: Table S1), 5 with terminal deletion of 9q (case 28-32, Additional file 2: Table
S2), and 3 with small (880-1001 kb in size) 9q34.3 deletions due to unbalanced translocations (case 45-47, Additional file 2: Table S2). Remarkably, we brought about three extremely small ( $22 \mathrm{~kb}, 39 \mathrm{~kb}$ and $40 \mathrm{~kb}$ in size) intragenic deletions of the EHMT1 gene and all were clustered at the 3 ' end of the gene (Fig. 3, b-d). The 22-kb deletion (Fig. 3b) was identified in a 32-year-old female with intellectual disability; whereas, the 40-kb deletion (Fig. 3c) was found in a 5-year-old girl and the 39-kb deletion (Fig. 3d) was discovered in a 1-year-old girl with typical features of 9q34.3 deletion including developmental delay, speech and motor delay, and hypotonia [9]. In addition, a 26-year-old male with a 165-kb deletion involving EHMT1 and CACNA1B gene (case 57, Additional file 2: Table S1) also presented clinical features which were typical for 9q34.3 deletion syndromes including mental retardation, developmental delay, speech delay, motor delay, learning disability, autism spectrum disorder, asymmetry of temporal lobe, localized polymicrogyria, loping gait and scoliosis [11].

In contrast to the EHMT1 gene of which haploinsufficiency score was much better established by ClinGen 
(https://www.ncbi.nlm.nih.gov/projects/dbvar/clingen/ ), the sensitivity to haploinsufficiency for DOCK 8 and $K A N K 1$ genes was not proven (Additional file 2: Table S3). There were two unrelated patients with mental retardation and developmental disability (MRD2; OMIM \#614113) who were disclosed to have a heterozygous disruption of the longest isoform of the DOCK 8 gene by either deletion or a translocation of $t(X ; 9)$ [12]. A recent report of another two patients with almost identical deletion involving both $D O C K 8$ and KANK1 displayed two distinct phenotypes [6]. The study of a four-generation with a 225$\mathrm{kb}$ deletion of the $K A N K 1$ gene implied that an imprinting mechanism may play a role in the phenotypic variation in this family. The authors suggested KANK1 is a maternally imprinted gene and only expressed in the paternal allele [8]. However, other report did not support this finding [7]. In our cohort, deletions of $K A N K 1$ were found in 6 cases (case 25-30, Additional file 2: Table S1). There were not enough clinical data to determine whether $K A N K 1$ is a maternally imprinted gene. On the other hand, DOCK 8 gene is unlikely to be maternally imprinted since the two half-brothers (a 2year-old boy and a 7-year-old boy, case 13 and 14, Additional file 2: Table S1) both inherited the deleted DOCK8 allele from the same mother. In addition, our patients with small deletions of the DOCK8 gene had very strong family history (case 13/14, 17, 20/21 Additional file 2: Table S1) and shared similar clinical features, including developmental delay and intellectual disability (4 out of 5 cases), speech and motor delay (3), learning disability (2), behavior problems or autism (3), macrocephaly (2), dysmorphic or congenital anomalies (4). Our cohort provided additional pathogenic evidence for haploinsufficiency of DOCK8 gene.

Although extremely rare, two cases with homozygous deletions of GLDC and CDK5RAP2 genes were discovered in this cohort. In our previous study, we demonstrated the autosomal recessive disorders could be linked to regions of homozygosity ( $\mathrm{ROH})$ containing gene with point mutation which was inherited from related parents [2]. In this study, we showed additional two cases with autosomal recessive disorders which can be identified by high-resolution oligo-SNP array. The first was due to inheritance of allele with heterozygous deletion of different size from each carrier parent, which led to a homozygous deletion of GLDC gene (Fig. 4). The second was a homozygous deletion of the CDK5RAP2 gene, inherited from closely related parents who carried the same heterozygous deletion (Additional file 3: Figure S2A). These two cases proved the efficacy of using high-resolution oligo-SNP array in the identification of extremely small homozygous pathogenic deletions.

\section{Conclusions}

This study demonstrated 1): the incidence of recurrent small pathogenic deletions $(<1 \mathrm{Mb})$ was approximately
$3 \%(373 / 13,000)$ of all reported CNVs; 2$)$ : the small pathogenic deletions at $9 \mathrm{p} 24.3$ and $9 \mathrm{q} 34.3$ constituted $12 \%$ of small pathogenic deletions from all the chromosomes, 3): $59 \%$ of pathogenic deletions on chromosome 9 were due to small $(<1 \mathrm{Mb})$ or relatively small (1$1.5 \mathrm{Mb}$ ) pathogenic deletions; 4): $81 \%(46 / 57)$ of small pathogenic deletions were enriched at 9 p24.3 and $9 \mathrm{q} 34.3$ regions involving the DOCK8, KANK1 and EHMT1 genes; 5): high-resolution oligo-SNP array was capable of identifying homozygous deletions as small as $25 \mathrm{~kb}$ in size.

\section{Methods \\ Patients}

Patients with a broad range of clinical indications including intellectual disability, developmental delay, multiple congenital anomalies, dysmorphic features and pervasive developmental disorders were referred to our laboratory for oligo-SNP array studies. The data for this study were compiled from de-identified results of 38,000 consecutive patient specimens referred to our laboratory for constitutional oligo-SNP array study from 2011 to 2015. The patients were majorly from general population in the United States, with $<5 \%$ from Mexico and other countries.

\section{Oligonucleotide-single nucleotide polymorphism array analysis platforms and threshold setting} Oligo-SNP array analysis was performed on either Human SNP Array 6.0 (in 2011) or CytoScan ${ }^{\bullet}$ HD (2012-2015)(Affymetrix, Santa Clara, CA), using genomic DNA extracted from whole blood. The Human SNP Array 6.0 has 1.8 million genetic markers, including about 906,600 SNPs and 946,000 probes for the detection of CNVs. The CytoScan ${ }^{\oplus} \mathrm{HD}$ has more than 2.67 million probes, including 1.9 million non-polymorphic copy number probes and 750,000 SNP probes. The overall resolutions are approximately $1.7 \mathrm{~kb}$ for Human SNP Array 6.0 and $1.15 \mathrm{~kb}$ for CytoScan ${ }^{\circ} \mathrm{HD}$. For chromosome 9, the probes for Human SNP Array 6.0 covered: $9 \mathrm{p}(\mathrm{chr} 9: 37,747-47,217,164)$ and $9 \mathrm{q}(\mathrm{chr} 9: 65,596,318$ 141,091,382); for CytoScan $\mathrm{HD}^{\bullet}$ : 9p (chr9:192,12940,784,142, chr9:43,400,082-44,900,526) and 9q (chr9:66, $837,485-141,025,328)$. Genomic coordinates were based upon genome build 37/hg19 (2009). Hybridization, data extraction, and analysis were performed as per manufacturers' protocols. The Affymetrix ${ }^{\odot}$ Chromosome Analysis Suite (ChAS) Software version 2.0 was used for data analysis, review, and reporting. For genome-wide screening, thresholds were set at $>200 \mathrm{~kb}$ for gains and $>50 \mathrm{~kb}$ for losses. For cytogenetically relevant regions, thresholds were set at $>100 \mathrm{~kb}$ for gains and $>20 \mathrm{~kb}$ for losses. Benign CNVs that are documented in the database of genomic variations (http://dgv.tcag.ca/dgv/app/home?ref=GRCh37/hg19) and present in the general population were excluded from reporting. 


\section{Additional files}

Additional file 1: Figure S1. Profile of abnormal CNVs and VOUS in chromosome 9 from 531 cases. A total of 142 cases with pathogenic CNVs, and 389 cases with VOUS were identified. (JPG 52 kb)

Additional file 2: Table S1. List of the cases with small $(<1 \mathrm{Mb})$ pathogenic copy number loss on chromosome 9 without involvement of other chromosomes $(N=57)$. Table $\mathbf{S 2}$. List of the remaining cases with copy number loss on chromosome $9(N=47)$. Table S3. Interpretation, references and ClinGen evaluation of haploinsufficiency score of selected cytogenetically relevant genes on chromosome 9. (DOCX 43 kb)

Additional file 3: Figure S2. A. The finding of multiple large regions of homozygosity (421 Mb) was due to closely parental relatedness. B. An approximately 74-kb homozygous deletion involved multiple exons of the CDK5RAP2 gene in a region of homozygosity at 9q33.1-q34.11 (chr9:118,503,864-132,425,233), which caused autosomal recessive primary microcephaly-3 (OMIM \#604804). (JPG 60 kb)

\section{Abbreviations}

CMA: Chromosomal microarray analysis; CNV: Copy number variant; FISH: Fluorescence in situ hybridization; ISCN: International System of Cytogenetic Nomenclature; Oligo-SNP array: Oligonucleotide-single nucleotide polymorphism array; UPD: Uniparental disomy; VOUS: Variants of uncertain clinical significance

\section{Acknowledgements}

The authors acknowledge that Andrew Hellman and Jeff Radcliff provided valuable assistance in manuscript revisions.

\section{Funding}

Not applicable.

\section{Availability of data and materials}

The raw data and materials used for this study have been de-identified and were freely available to any scientist wishing to use them without breaching participant confidentiality.

\section{Authors' contributions}

J-CW - reviewing, verification, analysis and interpretation of the data, drafting and revising the article, final approval of the version to be published. LWM acquisition, reviewing and analysis of data. LPR - acquisition, reviewing and analysis of data. AA - conception and design, interpretation of data. RO interpretation of data. FZB - interpretation of data. All authors read and approved the final manuscript.

\section{Competing interests}

The authors declare that they have no competing interests.

\section{Consent for publication}

Not applicable since this manuscript did not contain any individual's personal data in any form.

\section{Ethics approval and consent to participate}

This manuscript is a retrospective case report that does not require ethics committee approval at our institution. Consent was considered not required because the cases reported here were anonymous and de-identified.

\section{Received: 24 August 2016 Accepted: 1 November 2016}

Published online: 15 November 2016

\section{References}

1. Watson CT, Marques-Bonet T, Sharp AJ, Mefford HC. The genetics of microdeletion and microduplication syndromes: an update. Annu Rev Genomics Hum Genet. 2014;15:215-44.

2. Wang JC, Ross L, Mahon LW, Owen R, Hemmat M, Wang BT, El Naggar M, Kopita KA, Randolph LM, Chase JM, Matas Aguilera MJ, Siles JL, Church JA, Hauser N, Shen J, Jones MC, Wierenga KJ, Jiang Z, Haddadin M, Boyar FZ, Anguiano A, Strom CM, Sahoo T. Regions of homozygosity identified by oligonucleotide SNP arrays: evaluating the incidence and clinical utility. Eur Hum Genet. 2015:23:663-71.

3. Liehr T. Cytogenetic contribution to uniparental disomy (UPD). Mol Cytogenet. 2010;3:8.

4. Bena F, Bruno DL, Eriksson M, van Ravenswaaij-Arts C, Stark Z, Dijkhuizen T, Gerkes E, Gimelli S, Ganesamoorthy D, Thuresson AC, Labalme A, Till M, Bilan F, Pasquier L, Kitzis A, Dubourgm C, Rossi M, Bottani A, Gagnebin M, Sanlaville D, Gilbert-Dussardier B, Guipponi M, van Haeringen A, Kriek M, Ruivenkamp C, Antonarakis SE, Anderlid BM, Slater HR, Schoumans J. Molecular and clinical characterization of 25 individuals with exonic deletions of NRXN1 and comprehensive review of the literature. Am J Med Genet B Neuropsychiatr Genet. 2013;162B:388-403.

5. Soorya L, Kolevzon A, Zweifach J, Lim T, Dobry Y, Schwartz L, Frank Y, Wang AT, Cai G, Parkhomenko E, Halpern D, Grodberg D, Angarita B, Willner JP, Yang A, Canitano R, Chaplin W, Betancur C, Buxbaum JD. Prospective investigation of autism and genotype-phenotype correlations in 22q13 deletion syndrome and SHANK3 deficiency. Mol Autism. 2013:4:18.

6. Tassano E, Accogli A, Pavanello M, Bruno C, Capra V, Gimelli G, Cuoco C. Interstitial 9p24.3 deletion involving only DOCK8 and KANK1 genes in two patients with non-overlapping phenotypic traits. Eur J Med Genet. 2016;59:20-5.

7. Vanzo RJ, Martin MM, Sdano MR, South ST. Familial KANK1 deletion that does not follow expected imprinting pattern. Eur J Med Genet. 2013:56:256-9.

8. Lerer I, Sagi M, Meiner V, Cohen T, Zlotogora J, Abeliovich D. Deletion of the ANKRD15 gene at 9p24.3 causes parent-of-origin-dependent inheritance of familial cerebral palsy. Hum Mol Genet. 2005;14:3911-20.

9. Kleefstra T, van Zelst-Stams WA, Nillesen WM, Cormier-Daire V, Houge G, Foulds $\mathrm{N}$, van Dooren $\mathrm{M}$, Willemsen MH, Pfundt $\mathrm{R}$, Turner A, Wilson M, McGaughran J, Rauch A, Zenker M, Adam MP, Innes M, Davies C, Lopez AG, Casalone R, Weber A, Brueton LA, Navarro AD, Bralo MP, Venselaar H, Stegmann SP, Yntema HG, van Bokhoven H, Brunner HG. Further clinical and molecular delineation of the $9 \mathrm{q}$ subtelomeric deletion syndrome supports a major contribution of EHMT1 haploinsufficiency to the core phenotype. J Med Genet. 2009:46:598-606.

10. Shao L, Shaw CA, Lu XY, Sahoo T, Bacino CA, Lalani SR, Stankiewicz P, Yatsenko SA, Li Y, Neill S, Pursley AN, Chinault AC, Patel A, Beaudet AL, Lupski JR, Cheung SW. Identification of chromosome abnormalities in subtelomeric regions by microarray analysis: a study of 5,380 cases. Am J Med Genet A. 2008;146A:2242-51.

11. Willemsen MH, Vulto-van Silfhout AT, Nillesen WM, Wissink-Lindhout WM, van Bokhoven H, Philip N, Berry-Kravis EM, Kini U, van Ravenswaaij-Arts CM, Delle Chiaie B, Innes AM, Houge G, Kosonen T, Cremer K, Fannemel M, Stray-Pedersen A, Reardon W, Ignatius J, Lachlan K, Mircher C, van den Enden PT H, Mastebroek M, Cohn-Hokke PE, Yntema HG, Drunat S, Kleefstra T. Update on Kleefstra Syndrome. Mol Syndromol. 2012;2:202-12.

12. Griggs BL, Ladd S, Saul RA, DuPont BR, Srivastava AK. Dedicator of cytokinesis 8 is disrupted in two patients with mental retardation and developmental disabilities. Genomics. 2008;91:195-202.
Submit your next manuscript to BioMed Central and we will help you at every step:

- We accept pre-submission inquiries

- Our selector tool helps you to find the most relevant journal

- We provide round the clock customer support

- Convenient online submission

- Thorough peer review

- Inclusion in PubMed and all major indexing services

- Maximum visibility for your research

Submit your manuscript at www.biomedcentral.com/submit
Biomed Central 